\title{
Compatibility Studies on Elastomers and Polymers with Ethanol Blended Gasoline
}

\author{
J. S. Dhaliwal, M. S. Negi, G. S. Kapur, and Shashi Kant \\ Indian Oil Corporation Limited, R\&D Division, Sector 13, Faridabad, Haryana 121007, India \\ Correspondence should be addressed to G. S. Kapur; kapurgs@indianoil.in
}

Received 26 June 2013; Accepted 29 October 2013; Published 29 January 2014

Academic Editors: X. Lu and A. W. Mohammad

Copyright (C) 2014 J. S. Dhaliwal et al. This is an open access article distributed under the Creative Commons Attribution License, which permits unrestricted use, distribution, and reproduction in any medium, provided the original work is properly cited.

This paper reports the compatibility studies of $10 \%$ ethanol blended gasoline (E10) with four types of elastomer materials, namely, Neoprene rubber, Nitrile rubber, hydrogenated Nitrile butadiene rubber (HNBR), and Polyvinyl chloride/Nitrile butadiene rubber blend (PVC/NBR), and two types of plastic materials, namely, Nylon-66 and Polyoxymethylene (Delrin). These materials have applications in automotives as engine seals, gaskets, fuel system seals and hoses, and so forth. Two types of the ethanol blended gasoline mixtures were used: (a) gasoline containing 5\% ethanol (E5), which is commercial form of gasoline available in India, and (b) gasoline containing 10\% ethanol (E10). The above materials were immersed in E5 and E10 for 500 hrs at $55^{\circ} \mathrm{C}$. A set of eight different properties in E5 and E10 (visual inspection, weight change, volume change, tensile strength, percent elongation, flexural strength, impact strength, and hardness) were measured after completion of $500 \mathrm{hrs}$ and compared with reference specimens (specimens at $55^{\circ} \mathrm{C}$ without fuel and specimens at ambient conditions). Variation observed in different materials with respect to the above eight properties has been used to draw inference about the compatibility of these elastomeric/polymer materials with E10 fuel vis-à-vis E5 fuels. The data presented in this study is comparative in nature between the results of E10 and E5.

\section{Introduction}

Ethanol is today used as an automotive fuel and currently $5 \%$ of ethanol is mixed in commercial gasoline available in India, though in many countries the dosage of ethanol in commercial gasoline can vary from 5 to $20 \%$ and even up to $86 \%$ in Brazil. Though ethanol blended gasoline has its own advantages, there are certain issues associated with its usage. Blending of ethanol leads to formation of azeotrope with lower boiling point which results in higher volatility of blend and its higher vapor pressure $[1,2]$. Ethanol molecules can also result in breaking bond between resins and fillers in fiberglass gas tanks, causing them to leak, resulting in sticking of resins to valves and other internal engine parts causing deposits and clogged intake valves. Another problem of blending ethanol in gasoline is that, ethanol attracts water, leading to increased corrosion in metal gas tanks, increased knocking, and decreased performance. Another important issue is the compatibility of various elastomer and plastic materials of different chemistry, used in different automobile parts, with ethanol. These issues have been studied and addressed in various internal studies and research papers [317]. A major study on 20 percent ethanol blended gasoline (E20) has been reported by the Orbital Engine Company, Australia, for the Government of Australia [3-5]. This study was focused on the effect of E20 on automobiles and small engines in regard to emissions, drivability, and material compatibility. Study found that E20 caused significant problems in many plastic, rubber, and metal components.

In 2008, Minnesota Center for Automotive Research, USA, carried out extensive work on the effect of blending ethanol in different percentages with gasoline on different types of polymers and elastomers used in automotives, marines, small engines fuel systems, and fuel dispensing equipment $[7,8]$. Three types of fuel mixtures (50/50 toluene isooctane mixture, $10 \%$ ethanol in gasoline, and $20 \%$ ethanol in gasoline) were used to investigate their effect on 8 different types of polymers and elastomers (Nylon-66, Nylon-6, Polyethylene terephthalate (PET), Polyvinyl chloride (PVC), Polybutylene terephthalate (PBT), Acrylonitrile butadiene styrene (ABS), Acrylic rubber (ACM), Epichlorohydrin rubber (CO), Polychloroprene rubber (CR), Nitrile/PVC blend, 
TABLE 1: Showing specimen dimensions used for studies.

\begin{tabular}{lclcc}
\hline S. number & Specimen type & Specimen dimension & Reference \\
\hline & & Elastomers & \\
1 & Visual appearance & $1^{\prime \prime} \times 2^{\prime \prime} \times .08(\mathrm{t})($ rectangular shaped) & {$[9]$} \\
2 & Tensile strength & $115 \times 25 \times 2 \mathrm{~mm} \pm 0.25$ Type C (dumbbell shaped) & {$[10]$} \\
3 & Hardness & Done on tensile specimens & {$[11]$} \\
\hline & Plastics & {$[9]$} \\
5 & Visual appearance & $2^{\prime \prime}$ dia $\times 0.125(\mathrm{t})($ disk shaped $)$ & {$[12]$} \\
6 & Tensile strength & $165 \times 19 \times 1.6 \mathrm{~mm}$ Type $1($ dumbbell shaped $)$ & {$[13]$} \\
7 & Izod impact & $63.5(\mathrm{l}) \times 12.7(\mathrm{w}) \times 2.54($ notch $) \times 3.175(\mathrm{t}) \mathrm{mm}$ & \\
\hline
\end{tabular}

etc.). Different materials responded differently depending upon the fuel system. Four polymer materials Nylon-6, Nylon-66, PET, and Polyetherimide (PEI) showed good compatibility towards each type of fuel.

As the Government of India is contemplating an increase in the blending percentage of ethanol in commercial gasoline from $5 \%$ to $10 \%$, in the present work, compatibility studies of four types of elastomer materials, that is, Neoprene, Polyvinyl chloride/Nitrile butadiene rubber blend (PVC/NBR), hydrogenated Nitrile butadiene rubber (HNBR), and Nitrile rubber, and two types of plastic materials (Nylon-66 and Delrin) in $10 \%$ ethanol blended gasoline (E10) have been carried out vis-à-vis 5\% ethanol blended gasoline (E5). Eight properties (visual inspection, weight change, volume change, tensile strength, percent elongation, flexural strength, impact strength, and hardness) were measured after completion of $500 \mathrm{hrs}$ of testing in E5 and E10 and the results compared with reference specimens (specimens at $55^{\circ} \mathrm{C}$ without fuel and specimens at ambient temperature). Variation observed in different materials with respect to above eight properties has been used to draw inference about the compatibility of these polymeric materials with E10 fuel vis-à-vis E5 fuels.

\section{Experimental}

2.1. Materials. Four types of elastomers, namely, Neoprene rubber, Nitrile rubber, hydrogenated Nitrile butadiene rubber (HNBR), and Polyvinyl chloride/Nitrile butadiene rubber blend (PVC/NBR), and two types of plastic materials, namely, Nylon-66 and Polyoxymethylene (Delrin), were thankfully made available by $\mathrm{M} / \mathrm{s}$ Tata Motors Limited and Honda Siel Cars India Limited.

\subsection{Specimens Preparation}

2.2.1. Elastomers and Plastics. In case of elastomers, specimens of two different shapes were made, whereas three different shaped test specimens were required for plastic testing. Five specimens per fuel per material were used for each testing related to change in appearance, tensile strength, and flexural strength. For measuring the Izod impact, ten specimens per fuel per plastic type were used [18]. Further, one set of specimens of each elastomer and plastic type were
TABLE 2: Showing physiochemical properties of ethanol.

\begin{tabular}{llc}
\hline $\begin{array}{l}\text { S. } \\
\text { number }\end{array}$ & Characteristics/property & Value \\
\hline 1 & Appearance visual & Clear \& bright \\
2 & Specific gravity at $60^{\circ} \mathrm{F}$ & 0.7942 \\
3 & Purity $(\%, \mathrm{v} / \mathrm{v})$ & $99.88 \%, \mathrm{v} / \mathrm{v}$ \\
4 & Acidity (as $\left.\mathrm{CH}_{3} \mathrm{COOH}\right) \mathrm{mg} / \mathrm{L}$ & $11.3 \mathrm{mg} / \mathrm{L}$ \\
5 & Aldehyde content $\left(\right.$ as $\left.\mathrm{CH}_{3} \mathrm{CHO}\right) \mathrm{mg} / \mathrm{L}$ & $<60 \mathrm{mg} / \mathrm{L}$ \\
6 & Copper $\mathrm{mg} / \mathrm{kg}$ & 0.094 \\
7 & Miscibility with water & Miscible \\
\hline
\end{tabular}

used as reference specimens. The set of five specimens were hanged in the bottles at $55+2^{\circ} \mathrm{C}$ without fuel and were termed as Air-55. Table 1 shows the various types of specimens used and their dimensions.

\subsection{Testing Procedures}

2.3.1. Fuels Used. SAE J1748 [18] describes methods for determination of physical properties of polymeric materials exposed to gasoline/oxygenate fuel mixtures. SAE J1748 applies to determining worst case fuel, conditioning test specimens in these fuels prior to testing; various tests for determination of properties and typical calculations used are mentioned in this test. SAE J1748 was taken as main reference in our study; dimensions of the specimens, conditioning parameters, and testing protocols were taken into account as per standard. Table 2 shows the characteristic properties of ethanol used in the study. Two different types of fuels were used for the study. First type of fuel used had 5\% ethanol blended gasoline, which is currently used as commercial fuel in India (E5). Second type of fuel used had 10\% ethanol blended in gasoline (E10). Table 3 shows detailed physiochemical properties of fuel used for the study.

2.3.2. Preimmersion Measurements. Before the specimens were immersed, after conditioning as per ASTM D618 [19], both types of samples (elastomers and plastics) were weighted on an analytical balance up to four decimal places $[18,20$, 21]. Volume of all the appearance specimens was measured both in air and fuels. Further, hardness of all the elastomer 
TABLE 3: Showing physiochemical properties of fuels.

\begin{tabular}{llcc}
\hline $\begin{array}{l}\text { S. } \\
\text { number }\end{array}$ & Properties & E5 & E10 \\
\hline 1 & Color & Pale yellow & $\begin{array}{c}\text { Light } \\
\text { orange }\end{array}$ \\
2 & Density, at 15 deg. C, $\mathrm{kg} / \mathrm{m}^{3}$ & 741.1 & 754.4 \\
3 & Octane number & 92.8 & 95 \\
4 & Sulphur (ppm) & 110 & 105 \\
5 & Lead content, g/L, mx & $<10 \mathrm{ppm}$ & $<10 \mathrm{ppm}$ \\
6 & Benzene content, \% vol & 0.74 & 0.6 \\
7 & Olefin content, \% vol & 19.91 & 17.8 \\
8 & Aromatics content, \% vol & 28.23 & 28.0 \\
\hline
\end{tabular}

specimens was measured at the clamping ends of tensile specimens since this will not influence the tensile testing [22].

2.3.3. Specimen Immersion in Test Fuels. Five specimens of each elastomer and plastic type were immersed in E5 and E10 fuels for a continuous period of $500 \mathrm{hrs}$ at $55+2^{\circ} \mathrm{C}$. Besides, the specimens were also kept in Air (i.e., without fuels) at ambient as well as at $55+2^{\circ} \mathrm{C}$ (i.e., without fuels) for 500 hours. Specimens were placed and suspended in glass bottles in such manner to avoid contact with the walls or bottom of the container using aluminum wires. Glass beads were used to separate specimens from one another. Appearance specimens of plastics and elastomers, plastic impact, and flexural specimens were immersed in $500 \mathrm{~mL}$ bottles whereas for plastic tensile specimens $2 \mathrm{~L}$ bottles were used. Glass bottles were filled with appropriate test fluids until the fluid level was $3 \mathrm{~cm}$ above the top of the specimens as per ASTM D471 [23] and were placed in oven to reach $55^{\circ} \mathrm{C}$ $\pm 2^{\circ} \mathrm{C}$. Once temperature in ovens was stabilized, specimens were placed inside the bottles. Fuels in each bottle were replaced daily for the first three days and weekly thereafter for elastomers; for plastics it was replaced weekly [18]. The immersion of the specimens was continued up to 500 hours. After completion of 500 hours, prior to the testing, specimens were treated under two different conditions, which are as follows.

(1) Specimens of both elastomers and plastics, after $500 \mathrm{hrs}$ of immersion in fuel, were wiped with a tissue to soak the surface gasoline-WET specimen.

(2) Specimens of elastomers, after $500 \mathrm{hrs,} \mathrm{were} \mathrm{dried} \mathrm{for}$ $40 \mathrm{hrs}$ in an oven at $55^{\circ} \mathrm{C}$ before taking measurement (only for elastomers) - DRY specimen.

2.3.4. Properties Measured and Procedures. The following properties were measured before and after the tests were completed and compared with reference samples. Appearance, weight, and volume change properties were determined on the same set of specimens.

Appearance. After completion of $500 \mathrm{hrs,} \mathrm{glass} \mathrm{containers}$ were removed from the oven and allowed to cool for 24 hours before the measurements were taken. Photographs and visual inspection of the specimens were noted before immersion, after immersion (WET), and after complete dryout (DRY), in order to observe any changes in color, surface texture, gloss, cracking, and so forth. While small changes in color and gloss are generally acceptable, changes in texture, cracking, and so forth are considered unacceptable as these may lead to component failure.

Weight Change. Specimens were dried with filter paper (WET) and weighted within 10 seconds to minimize evaporative weight loss. Specimens' weight were measured before immersion, after immersion (WET), and after complete dryout (DRY) and were compared with each other. Further, changes in weight of WET and DRY specimens were compared in E10 and E5, in order to see the effect of fuel composition. Comparison between change in weight of specimen before and after immersion will indicate how much fuel was absorbed into the material; a similar comparison between the specimens before immersion and dryout (DRY) will indicate quantity of material leached out [18]. Specimens at $55^{\circ} \mathrm{C}$ inside oven without fuel were allowed to cool before carrying out weight measurements. For measuring the weight, SARTORIUS BP2215 analytical balance was used to measure the weight and volume of the test samples. The balance has a resolution of $0.0001 \mathrm{~g}$.

Volume Change. Similarly, specimens' volumes were measured before immersion, after immersion (WET), and after complete dryout (DRY) and were compared with each other. Further, change in volume of WET and DRY specimen was compared in E10 and E5, in order to see the effect of fuel composition. This change in volume will indicate swelling or shrinkage of the material in a particular fuel. Both excessive shrinkage and swelling are considered unacceptable because they can cause problems like accelerated wear and bending of material. Volume of the appearance specimens was measured by fluid displacement method [23] within 10 seconds after removing specimens from bottles. Specimens at $55^{\circ} \mathrm{C}$ inside oven without fuel were allowed to cool before carrying out measurements. The volume of each specimen was calculated using the following relation:

$$
V=\frac{(\mathrm{MA}-\mathrm{MF})}{d},
$$

where $V$ is volume (cc), MA is mass in Air (g), MF is mass in fuel $(\mathrm{g})$, and $d$ is density $(\mathrm{g} / \mathrm{cc})$.

Durometer Hardness. The hardness of the specimens was measured before immersion, after immersion (WET), and after complete dryout (DRY) and was compared with that of others. Further, change in hardness of WET and DRY specimen was compared in E10 and E5, in order to see the effect of fuel composition. Excessive hardening or softening of a material is not desirable as it can lead to component failure under load. In case of WET specimen, after cooling the specimens, hardness test was performed within 3 minutes to minimize dryout effect on tensile specimens clamping ends. Since the same tensile specimens were to be used for hardness testing, hardness measurements were taken on the clamping 
ends of the specimen [18]. Measurements were made on each specimen according to ASTM D2240 [22].

Tensile Strength and Percentage of Elongation. The tensile strengths of the specimens were measured before immersion, after immersion (WET), and after complete dryout (DRY) and were compared with each other. Further, change in tensile strength and percent elongation of WET and DRY specimen was compared in E10 and E5, in order to see the effect of fuel composition. The testing was carried out after completing hardness Test in case of elastomers, and specimens were immediately put into universal testing machine (UTM) for tensile measurements. TIRA test 2710 Universal Testing Machine (UTM) was used for measurement of tensile strength and percent elongation. Tensile testing was done at a rate of $5 \mathrm{~mm} / \mathrm{min} \pm 25 \%[21,24]$.

Impact Strength and Flexural Strength (Plastics Only). The impact and flexural strength of the specimens were measured before immersion and after immersion (WET). TIRA Test 2710 Universal Testing Machine (UTM) was used for measurement of flexural properties. After cooling, specimens were wiped with tissue paper (WET specimen) and testing was completed within 5 minutes to minimize the effects of dryout. For impact strength, CEAST RESIL Impact Tester was used to determine the impact strength. Notch was made on all the impact specimens as per ASTM requirement using Ceast notch cutter [25].

2.4. Other Apparatuses Used. The test specimens were placed in special glass bottles of two different sizes (2 liters and $500 \mathrm{~mL}$ ) from DURAN which have the capability of withstanding high temperature and pressure. Bottle lids were made of polypropylene with a special type of Teflon membrane at top of lid. Aluminum wires were used to suspend the samples in the test fluid and glass beads were used to keep the samples separated from each other during the soaking period (Figure 1(a)). Different specimens were placed in different bottles depending upon their dimensions. Ovens used for the study had a centrally mounted fan for circulating heated Air inside the oven having temperature range from $5^{\circ} \mathrm{C}$ to $250^{\circ} \mathrm{C}$, with an accuracy of $\pm 10^{\circ} \mathrm{C}$. SARTORIUS BP2215 analytical balance was used to measure the weight and volume of the test specimens. The balance had a resolution of $0.0001 \mathrm{~g}$.

\section{Results and Discussions}

\subsection{Visual Inspection}

\subsubsection{Elastomers}

(a) WET Specimens. Neoprene, E10 specimens were found to be relatively very soft and brittle when compared to E5 and Air-55 specimens. Pits and depressions were also observed in E10 specimen (Figure 1(b)). For Nitrile, HNBR, and PVC/NBR specimens, no significant change was observed either in E5 or in E10 specimens.

(b) DRY Specimens. Neoprene, E10 specimens became hard as compared to E5 specimens. Shrinkage was also observed in the E10 and E5 specimens after drying. Pits and depressions in neoprene specimens (Figure 1(b)) kept in E10 fuel give an indication that material has leached out during exposure time, which can potentially cause problems in the fuel system and engine. Leaching of a product represents rapid degradation of the material since it can clog up other components. No shrinkage was observed in E10 specimens of Nitrile, HNBR, and PVC/NBR elastomers. Minor change in gloss was seen in HNBR and PVC/NBR specimens.

3.1.2. Plastics. Nylon-66 E10 specimens (Figure 2(a)) showed significant change in color as compared to corresponding E5 specimens. Color of E10 specimens changed from offwhite to pale yellow, whereas slight yellowish tinge was observed in corresponding E5 specimens. No other visible change was observed. Slight change in color of Delrin E10 and E5 specimens was also observed (Figure 2(b)). However, no cracks, roughness, tackiness, or degradation was observed in either of the Nylon or Delrin specimens.

\subsection{Weight Change}

3.2.1. Elastomers. From Table 4, Neoprene, Nitrile, and HNBR, E10 WET specimens showed almost 100 percent increase in weight, compared to E5 WET specimens. However, in case of DRY specimens, both E5 and E10 showed almost similar decrease in weight, except in case of Neoprene, where E10 showed more decrease in weight compared to E5 specimens. E10 specimens of Neoprene showed more leaching than E5 specimens. In case of PVC/NBR specimens, both WET and DRY specimens of E10 and E5 showed decrease in weight. Though the decrease in case of E5 and E10 WET specimen were very less ( $<1 \mathrm{wt} \%)$, E5 and E10 DRY specimens showed a significant decrease of about $20 \%$ in weight. Air-55 specimens of each type of above elastomers also showed slight decrease in weight, which can be due to the evaporation of entrapped moisture or volatiles.

3.2.2. Plastics. E10 and E5 specimens of both Nylon-66 and Delrin showed marginal change in weight. Weight change in E10 specimens was observed to be lower than E5 specimens (Table 5). Decrease in weight by about 3 percent in Nylon66 Air-55 specimens can be attributed to the loss of absorbed moisture due to hygroscopic nature of Nylon.

\subsection{Volume Change}

3.3.1. Elastomers. E10 WET specimens of all elastomers showed 100 percent increase in volume compared to E5 WET specimens which can be attributed to more absorbance of ethanol by the specimens. From Table 4, due to swelling of specimens during exposure to E10 fuel, about 96\% increase in volume was observed in Neoprene E10 WET specimens. In case of DRY specimens, a decrease in volume ranging from $2 \%$ to $34 \%$ was observed in all types of elastomers. Neoprene and PVC/NBR showed maximum decrease in volume. The loss in volume in these elastomers is due to the shrinkage 


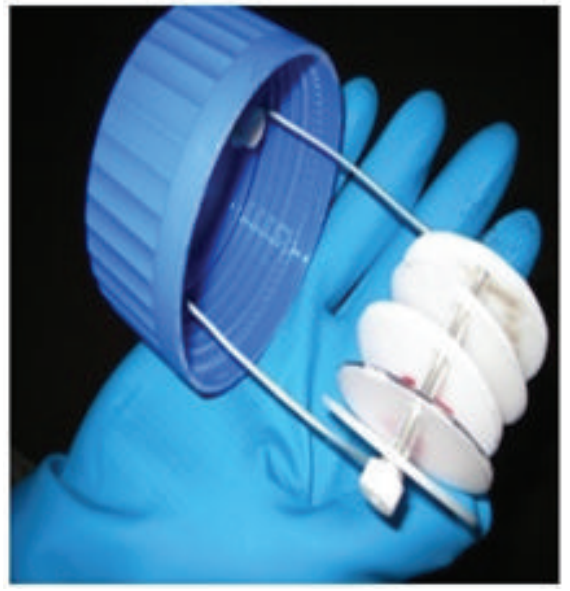

(a)

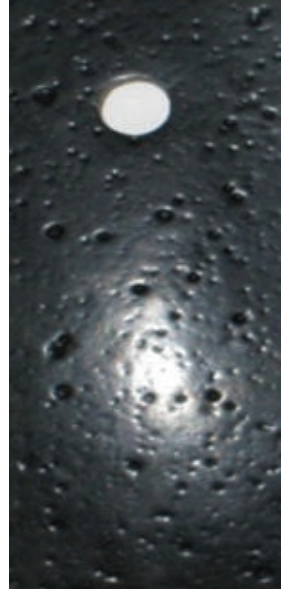

(b)

FIGURE 1: (a) Plastic specimens in hanging position from bottle lid separated with glass beads. (b) Neoprene E10 specimens after 500 hours of immersion.

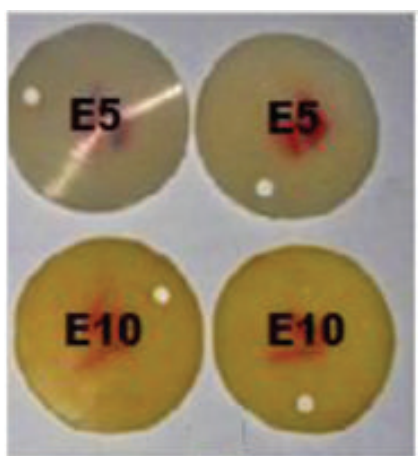

(a)

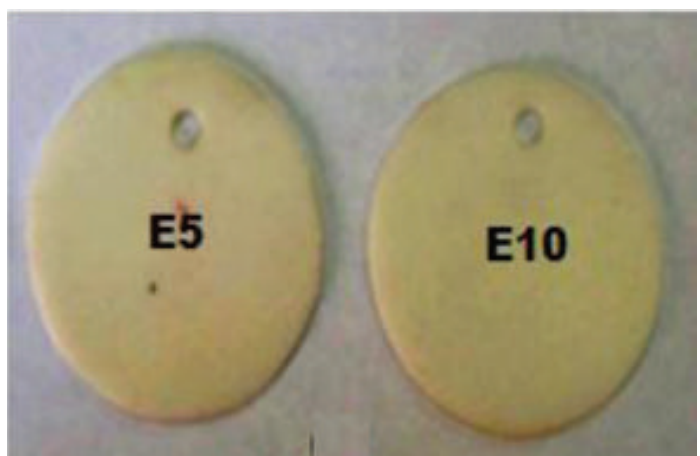

(b)

FIgUre 2: (a) Appearance specimens Nylon-66 E5 and E10. (b) Appearance specimens Delrin E5 and E10.

effect, which takes place during drying of these specimens, before the commencement of property measurement.

3.3.2. Plastics. Both Nylon- 66 and Delrin specimens placed in E5 and E10 specimens showed marginal change in volume.

\subsection{Tensile Strength and Elongation}

3.4.1. Elastomers. Decreasing trend in tensile strength was observed in both E5 and E10 WET specimens compared to corresponding Air-55 specimens. E10 WET specimens showed further reduction in the tensile strength compared to E5 WET specimens in Nitrile, HNBR, and PVC/NBR, whereas Neoprene decomposed completely in E10 fuel.

The tensile strength of all the E5 and E10 DRY specimens of elastomers increased as compared to WET specimens, with exception of Neoprene in E10 fuel. It was observed that Nitrile, HNBR, and PVC/NBR materials showed considerable reduction in percent elongation for both E5 and E10 WET specimens, when compared to Air-55 specimens. However, no difference was observed in case of E10 WET specimens to compared E5 WET specimens, which indicates that both E10 and E5 have similar effect on the values of elongation for these three elastomers. In case of Neoprene, E5 WET showed slightly higher value of elongation when compared to Air55 specimens, indicating some softening of the material. In HNBR, lower elongation was observed in E10 DRY compared to E5 and Air-55 specimens. However, comparing E10 and E5 DRY specimens data, while Nitrile showed increase in elongation, both HNBR and PVC/NBR showed reduction in elongation.

3.4.2. Plastics. Considerable reduction in the tensile strength was observed in case of E5 and E10 specimens of Nylon66 to Air-55 specimens (Table 5). A decrease of $33 \%$ in tensile strength of Nylon-66 E10 specimen as compared to E5 was observed. The tensile strength of Delrin E10 specimens, though found comparable to E5 specimens, was found to be lower than the Air-55 specimens. No significant change in elongation in E5 and E10 specimens of Nylon-66 was observed. Delrin E5 and E10 specimens showed higher elongation compared to Air-55 specimens. 
TABLE 4: Elastomers properties after immersion in fuels.

\begin{tabular}{|c|c|c|c|c|c|}
\hline Material & Air-55 & E5 WET & E10 WET & E5 DRY & E10 DRY \\
\hline \multicolumn{6}{|c|}{ Weight change (\%) } \\
\hline Neoprene & $-3.2 \pm 0.3$ & $24.8 \pm 0.6$ & $51.6 \pm 2.4$ & $-21.0 \pm 4.0$ & $-26.6 \pm 3.0$ \\
\hline Nitrile & $-0.7 \pm 0.02$ & $10.2 \pm 0.03$ & $21.9 \pm 0.2$ & $-7.1 \pm 0.06$ & $-6.4 \pm 0.1$ \\
\hline HNBR & $-0.7 \pm 0.1$ & $13.4 \pm 0.1$ & $25.9 \pm 1.4$ & $-4.1 \pm 0.3$ & $-3.0 \pm 0.6$ \\
\hline $\mathrm{PVC} / \mathrm{NBR}$ & $-0.6 \pm 0.2$ & $-0.9 \pm 0.1$ & $-0.4 \pm 0.1$ & $-20.1 \pm 0.1$ & $-20.1 \pm 0.1$ \\
\hline \multicolumn{6}{|c|}{ Volume change (\%) } \\
\hline Neoprene & $-4.5 \pm 1.0$ & $49.6 \pm 1.0$ & $96.3 \pm 4.0$ & $-28.4 \pm 4.0$ & $-34.2 \pm 3.0$ \\
\hline Nitrile & $-1.4 \pm 0.1$ & $20.5 \pm 4.0$ & $39.7 \pm 0.4$ & $-9.3 \pm 0.1$ & $-9.7 \pm 0.2$ \\
\hline HNBR & $-0.8 \pm 0.1$ & $19.4 \pm 7.0$ & $33.8 \pm 3.0$ & $-2.0 \pm 6.0$ & $1.0 \pm 3.0$ \\
\hline $\mathrm{PVC} / \mathrm{NBR}$ & $-1.2 \pm 0.3$ & $2.5 \pm 4.0$ & $5.3 \pm 2.0$ & $-25.2 \pm 3.0$ & $-27.3 \pm 2.0$ \\
\hline \multicolumn{6}{|c|}{ Tensile strength (Mpa) } \\
\hline Neoprene & $11 \pm 1$ & $8 \pm 0.5$ & - & $11 \pm 1$ & - \\
\hline Nitrile & $9 \pm 0.5$ & $4 \pm 0.5$ & $2 \pm 0.5$ & $8 \pm 2$ & $10 \pm 1$ \\
\hline HNBR & $19 \pm 1$ & $8 \pm 1$ & $3 \pm 1$ & $18 \pm 2$ & $12 \pm 1$ \\
\hline PVC/NBR & $10 \pm 0.5$ & $8 \pm 0.5$ & $6 \pm 1$ & $11 \pm 1$ & $10 \pm 0.5$ \\
\hline \multicolumn{6}{|c|}{ Elongation (\%) } \\
\hline Neoprene & $146 \pm 30$ & $154 \pm 3$ & - & $81 \pm 9$ & - \\
\hline Nitrile & $102 \pm 4$ & $56 \pm 6$ & $56 \pm 10$ & $79 \pm 11$ & $92 \pm 6$ \\
\hline HNBR & $204 \pm 53$ & $149 \pm 24$ & $147 \pm 42$ & $201 \pm 29$ & $131 \pm 19$ \\
\hline $\mathrm{PVC} / \mathrm{NBR}$ & $115 \pm 4$ & $85 \pm 4$ & $83 \pm 6$ & $51 \pm 7$ & $33 \pm 3$ \\
\hline \multicolumn{6}{|c|}{ Shore hardness } \\
\hline Neoprene & $74 \pm 1$ & $50 \pm 3$ & - & $83 \pm 1$ & - \\
\hline Nitrile & $73 \pm 4$ & $67 \pm 2$ & $63 \pm 1$ & $80 \pm 2$ & $82 \pm 3$ \\
\hline HNBR & $73 \pm 1$ & $57 \pm 3$ & $44 \pm 6$ & $68 \pm 3$ & $67 \pm 2$ \\
\hline $\mathrm{PVC} / \mathrm{NBR}$ & $75 \pm 2$ & $72 \pm 3$ & $63 \pm 1$ & $77 \pm 3$ & $78 \pm 2$ \\
\hline
\end{tabular}

TABLE 5: Plastics properties after immersion in fuels.

\begin{tabular}{|c|c|c|c|c|c|}
\hline & Air-55 & E5 WET & E5 DRY & E10 WET & E10 DRY \\
\hline \multicolumn{6}{|c|}{ Weight change (\%) } \\
\hline Nylon-66 & $-3.1 \pm 0.1$ & $-3.0 \pm 0.1$ & -NA- & $-1.0 \pm 0.02$ & -NA- \\
\hline Delrin & $-0.3 \pm 0.01$ & $1.0 \pm 0.1$ & -NA- & $1.5 \pm 0.1$ & -NA- \\
\hline \multicolumn{6}{|c|}{ Volume change (\%) } \\
\hline Nylon-66 & $-4.0 \pm 1.0$ & $-3.9 \pm 1.4$ & -NA- & $-1.1 \pm 0.1$ & -NA- \\
\hline Delrin & $-1.0 \pm 0.1$ & $1.1 \pm 0.1$ & -NA- & $2.0 \pm 0.03$ & -NA- \\
\hline \multicolumn{6}{|c|}{ Tensile strength (Mpa) } \\
\hline Nylon-66 & $72 \pm 1$ & $51 \pm 9$ & -NA- & $34 \pm 13$ & -NA- \\
\hline Delrin & $63 \pm 1$ & $53 \pm 3$ & -NA- & $53 \pm 1$ & -NA- \\
\hline \multicolumn{6}{|c|}{ Elongation (\%) } \\
\hline Nylon-66 & $12 \pm 5$ & $5 \pm 1$ & -NA- & $6 \pm 3$ & -NA- \\
\hline Delrin & $8 \pm 4$ & $10 \pm 3$ & -NA- & $15 \pm 2$ & -NA- \\
\hline \multicolumn{6}{|c|}{ Impact strength $(\mathrm{J} / \mathrm{m})$} \\
\hline Nylon-66 & $45 \pm 4$ & $35 \pm 5$ & -NA- & $61 \pm 11$ & -NA- \\
\hline Delrin & $36 \pm 4$ & $45 \pm 7$ & -NA- & $46 \pm 11$ & -NA- \\
\hline \multicolumn{6}{|c|}{ Flexural strength (Mpa) } \\
\hline Nylon-66 & $7 \pm 1$ & $8 \pm 1$ & -NA- & $5 \pm 0.5$ & -NA- \\
\hline Delrin & $7 \pm 0.2$ & $6 \pm 0.3$ & -NA- & $5 \pm 0.2$ & -NA- \\
\hline
\end{tabular}


TABLE 6: Comparison of E10 versus E5 after 500 hours of immersion, by taking E5 as the reference data.

\begin{tabular}{|c|c|c|c|c|c|c|c|c|c|c|c|c|}
\hline \multirow{2}{*}{ Material } & \multicolumn{2}{|c|}{ Appearance } & \multicolumn{2}{|c|}{ Weight change } & \multicolumn{2}{|c|}{ Volume change } & \multicolumn{2}{|c|}{ Hardness } & \multicolumn{2}{|c|}{ Tensile } & \multicolumn{2}{|r|}{ Elongation } \\
\hline & WET & DRY & WET & DRY & WET & DRY & WET & DRY & WET & DRY & WET & DRY \\
\hline Neoprene & Pitting & $\begin{array}{l}\text { Pitting } \\
\text { and brittle }\end{array}$ & $+100 \%$ & No & $+100 \%$ & No & \multicolumn{6}{|c|}{ Sample got decomposed/crumbled completely } \\
\hline Nitrile & No & No & $+100 \%$ & No & $+100 \%$ & No & -4 units & No & $-100 \%(2 \mathrm{MPa})$ & No & No & No \\
\hline HNBR & No & No & $+100 \%$ & No & $+100 \%$ & No & -13 units & No & $-62 \%(5 \mathrm{MPa})$ & $-33 \%(6 \mathrm{MPa})$ & No & $-35 \%(70 \mathrm{~mm})$ \\
\hline $\mathrm{PVC} / \mathrm{NBR}$ & No & No & No & No & No & No & -11 units & No & $-25 \%(2 \mathrm{MPa})$ & No & No & $-35 \%(18 \mathrm{~mm})$ \\
\hline Material & \multicolumn{2}{|c|}{ Appearance } & \multicolumn{2}{|c|}{ Weight change } & $\begin{array}{l}\text { Volume } \\
\text { change }\end{array}$ & \multicolumn{2}{|c|}{ Impact strength } & Tensile & \multicolumn{2}{|c|}{ Elongation } & \multicolumn{2}{|r|}{ Flexural } \\
\hline Nylon-66 & \multicolumn{2}{|c|}{ Significant change } & \multicolumn{2}{|c|}{ No } & No & \multicolumn{2}{|c|}{$+74 \%(26 \mathrm{~J} / \mathrm{m})$} & No & \multicolumn{2}{|c|}{ No } & \multicolumn{2}{|c|}{$-37 \%(3 \mathrm{MPa})$} \\
\hline Delrin & \multicolumn{2}{|r|}{ No } & \multicolumn{2}{|c|}{ No } & No & \multicolumn{2}{|c|}{ No } & No & \multicolumn{2}{|c|}{ No } & \multicolumn{2}{|r|}{ No } \\
\hline
\end{tabular}

(-): decrease; (+): increase; No: no difference between E5 and E10 (within repeatability).

\subsection{Shore Hardness}

3.5.1. Elastomers. Neoprene E10 specimens were decomposed during test period so hardness was only performed on E5 specimens. The WET specimens of all the elastomers in E5 and E10 fuels became softer when compared to Air-55 specimens, with specimens in E10 showing more softening compared to E5. After the dryout, Neoprene E5 and Nitrile E5 and E10 specimens became harder, while HNBR specimens were slightly softer, compared to Air-55 specimens. The E5 and E10 DRY PVC/NBR specimens showed no change in hardness compared to Air-55 specimens. Shore hardness of E10 DRY specimens was comparable with E5 DRY specimens in all the elastomers (except Neoprene). For WET specimens, the hardness of E10 specimens was found to be lower than the E5 specimens.

\subsection{Impact and Flexural Properties}

3.6.1. Plastics. It was observed that the impact strength of E5 specimens of Nylon-66 decreased whereas impact strength of E10 specimens increased compared to Air-55 specimens. Delrin E5 and E10 specimens showed slightly better strength compared to Air-55 specimens. Nylon-66 E10 specimens showed higher impact strength than E5 specimens whereas no change was observed for Delrin E5 and E10 specimens. For Nylon-66, flexural strength of E5 specimens was found to be comparable to Air-55 specimens whereas flexural strength of E10 specimens was lower. From the results, it was observed that E10 specimens of both Nylon-66 and Delrin showed lower change in flexural strength as compared to E5 specimens.

\section{Summary}

The basic objective of the study was to compare the effects of E10 with respect to E5 type of fuel on the various types of elastomers and plastics found in automotive applications. Table 6 shows the changes observed in different materials in E10 vis-à-vis in E5; that is, data observed in E5 has been used as the reference. If E10 fuel did not result in a significant change in elastomer/plastic material compared to E5, then the material can be deemed compatible with E10 fuel. Pits and depressions were observed in Neoprene E10 visual appearance specimens. A $100 \%$ increase in weight and volume was observed in E10 specimens. Tensile specimens crumbled during exposure time. Results indicate that Neoprene is not compatible with E10 fuel. No major change in texture or shape in visual appearance specimens of both Nitrile and HNBR was observed. Weight and volume increased by $100 \%$ in specimens of both HNBR and Nitrile. Hardness and tensile strength of both elastomers decreased. From results, it can be concluded that both HNBR and Nitrile are not compatible with E10. PVC/NBR E10 specimens showed better resistance as compared to other elastomers. There was no significant change in E10 visual appearance, weight, or volume specimens as compared to E5 specimens. Since there was decrease in hardness and tensile strength of E10 specimens, HNBR can also can considered as incompatible with E10 fuel. Nylon visual appearance specimens color changed from off-white to pale yellow. An increase in impact strength and decrease in flexural strength of E10 specimens indicate that under long exposure E10 fuel can deteriorate the mechanical properties of Nylon-66 material. Thus Nylon-66 as such cannot be a favorable material for E10 fuel. Delrin showed good resistance towards E10 fuel. No significant change in physical and mechanical properties indicates that Delrin is compatible with E10 fuel.

\section{Conclusion}

To test and compare the effects of E10 fuel to those of E5 fuel, this study was conducted on four different elastomers and two types of plastics which come in contact of fuel directly or indirectly used in automotive engine fuel systems and fuel dispensing equipment. Both fuel types caused slight and drastic changes in some materials. In appearance specimens pits, depressions, and decomposition were observed in Neoprene E10 specimens. There was change in color of Nylon66 and Delrin E10 specimens. E10 showed significant effect on Nylon-66 and Delrin appearance specimens; there was visible change in color from off-white to pale yellow and creamish. Swelling was observed in all elastomers E5 and E10 WET specimens except PVC/NBR specimens, whereas all 
DRY specimens showed leaching signs. Maximum leaching was observed in PVC/NBR E5 and E10 specimens. There was about $100 \%$ increase in volume of all elastomers E10 WET specimens as compared to E5 WET specimens. Maximum shrinkage was observed in Neoprene dryout specimens. Delrin showed better resistance to shrinkage, swelling, and leaching as compared to Nylon-66. No uniform trend in tensile strength or elongation was observed in elastomer and plastic specimens. E10 WET specimens showed lower tensile strength as compared to E5 WET specimens but for DRY specimens' trend was nonuniform.

\section{Conflict of Interests}

The authors declare that there is no conflict of interests regarding the publication of this paper.

\section{Acknowledgments}

The authors wish to acknowledge the support of Tata Motors, Honda Motors, and SIAM (Society of Indian Automobile Manufacturers) for providing the samples and the management of Indian Oil Corporation Limited for permission to publish this work.

\section{References}

[1] R. Da Silva, R. Cataluña, E. W. D. Menezes, D. Samios, and C. M. S. Piatnicki, "Effect of additives on the antiknock properties and Reid vapor pressure of gasoline," Fuel, vol. 84, no. 7-8, pp. 951-959, 2005.

[2] J. A. Pumphrey, J. I. Brand, and W. A. Scheller, "Vapour pressure measurements and predictions for alcohol-gasoline blends," Fuel, vol. 79, no. 11, pp. 1405-1411, 2000.

[3] Orbital Engine Company Report, Market barriers to the uptake of biofuels study: A testing based assessment to determine impacts of a $10 \%$ and $20 \%$ ethanol gasoline fuel blend on nonautomotive engines-2000hrs material compatibility testing, 2003.

[4] Orbital Engine Company Report, Market barriers to the uptake of biofuels study: A testing based assessment to determine impacts of a $20 \%$ ethanol gasoline fuel blend on the Australian passenger vehicle fleet-2000hrs material compatibility testing, 2003.

[5] Orbital Engine Company Report, Market barriers to the uptake of biofuels study: A testing based assessment to determine impacts of a $20 \%$ ethanol gasoline fuel blend on the Australian passenger vehicle fleet, 2003.

[6] I. Nihalani, R. D. A. Paulmer, and Y. P. Rao, Compatibility of elastomeric materials with gasoline. SAE international technical paper number 2004-28-0062.

[7] B. Jones, G. Mead, and P. Steevens, "The effects of E20 on plastic automotive fuel system components," Tech. Rep. 20082/21/2008, Minnesota Center for Automotive Research.

[8] B. Jones, G. Mead, P. Steevens, and C. Connors, "The effects of E20 on elastomers automotive fuel system components," Tech. Rep. 2/22/2008, Minnesota Center for Automotive Research, 2008.
[9] A. Ertekin and N. Sridhar, "Performance of elastomeric materials in gasoline-ethanol blends-a review," NACE International Corrosion Conference, 2009.

[10] M. R. Shanmugam, N. Saravanan, L. Srinivasan, V. Hosur, and S. Sridhar, “. An experimental investigation on 1.4L MPFI gasoline engine to study its performance, emission and compatibility with E10 fuel," SAE International Technical Paper Number 2009-01-0611.

[11] E. W. Thomas, "Fluoroelastomer compatibility with bioalcohol fuels," SAE International Technical Paper 2009-01-0994.

[12] G. Micallef, "Elastomer selection for bio-fuel requires a systems approach," Sealing Technology, vol. 2009, no. 1, pp. 7-10, 2009.

[13] C. Berlanga-Labari, A. Albistur-Goñi, I. Barado-Pardo, M. Gutierrez-Peinado, and J. Fernández-Carrasquilla, "Compatibility study of high density polyethylene with bioethanolgasoline blends," Materials and Design, vol. 32, no. 1, pp. 441446, 2011.

[14] M. D. Kass, T. J. Theiss, C. J. Janke, S. J. Pawel, and S. A. Lewis, "Intermediate Ethanol Blends Infrastructure Materials compatibility study," Tech. Rep. ORNL/TM-2010/326, Elastomers, Metals, and Sealants Oak Ridge National Laboratory, 2011.

[15] M. D. Kass, T. J. Theiss, C. J. Janke, and S. J. Pawel, "Compatibility study for plastics, elastomeric and metallic fuelling infrastructure materials exposed to aggressive formulations of ethanol-blended gasoline," Tech. Rep. ORNL/TM-2012/88, Oak Ridge National Laboratory, 2012.

[16] V. M. D. Pasa, A. V. Maciel, J. C. Machado, and G. O. Barra, "Compatibility study of NBR/PVC blend with gasoline and ethanol fuel," Rubber Chemistry and Technology, vol. 85, pp. 195206, 2012.

[17] L. Baena, F. Jaramillo, and J. A. Calderón, "Aggressiveness of a $20 \%$ bioethanol $80 \%$ gasoline mixture on autoparts: II Behavior of polymeric materials," Fuel, vol. 95, pp. 312-319, 2012.

[18] Methods for determining physical properties of polymeric materials exposed to gasoline/oxygenate fuel mixtures: SAE J1748.

[19] Standard practice for conditioning plastics for testing: ASTM D618, 2010.

[20] Standard Practices for Evaluating the Resistance of Plastics to Chemical Reagents: ASTM D543, 2010.

[21] Standard test methods for rubber and thermoplastic elastomers-Tension: ASTM D412.

[22] Standard test methods for rubber properties-durometer hardness: ASTM D2240.

[23] Standard test methods for rubber property-Effect of liquid: ASTM D471.

[24] Standard test method for tensile properties of plastics: ASTM D638, 2010.

[25] Standard Test methods for determining the Izod pendulum impact resistance of plastics: ASTM D256, 2010. 


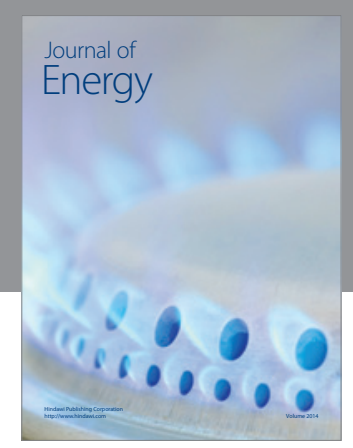

Journal of

Industrial Engineering
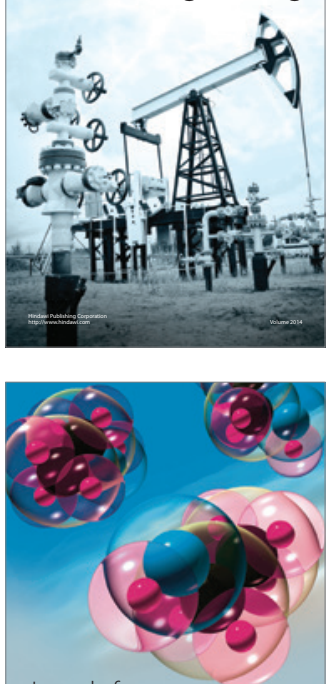

Fuels
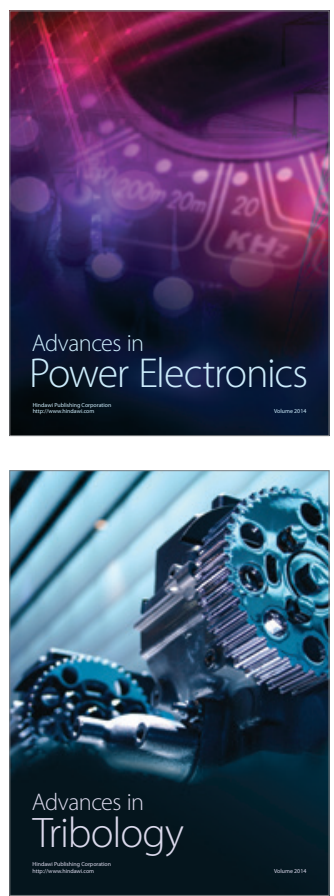

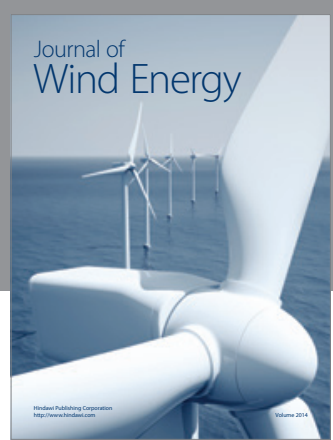

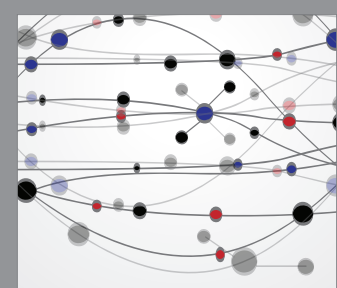

The Scientific World Journal

Submit your manuscripts at http://www.hindawi.com

Journal of

Structures
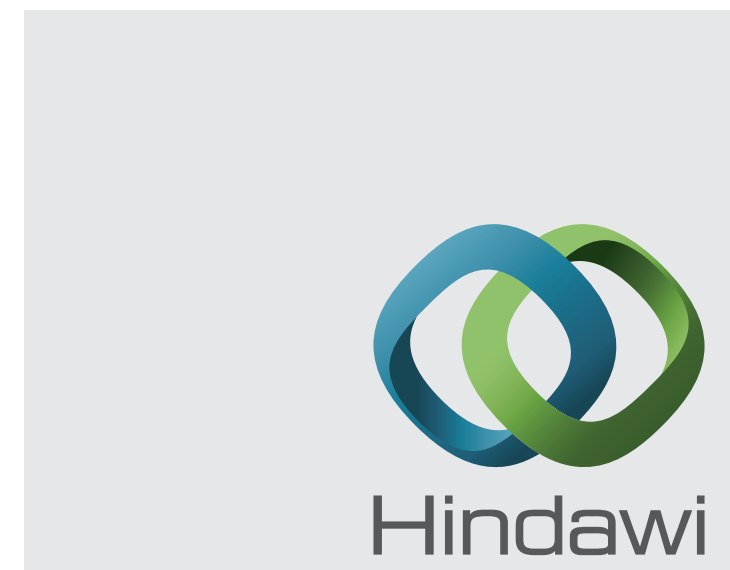

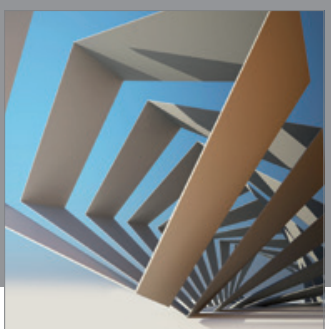

Rotating

Machinery
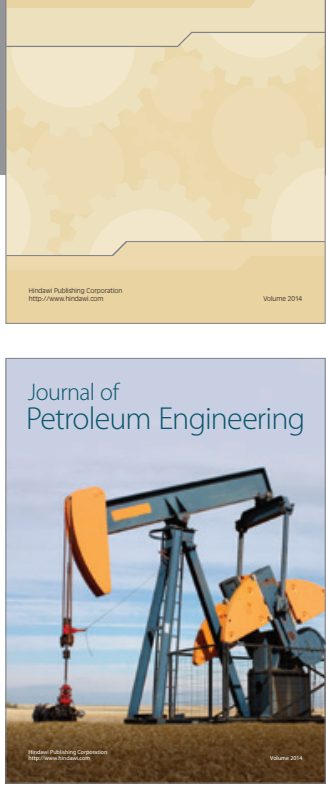

Journal of

Solar Energy
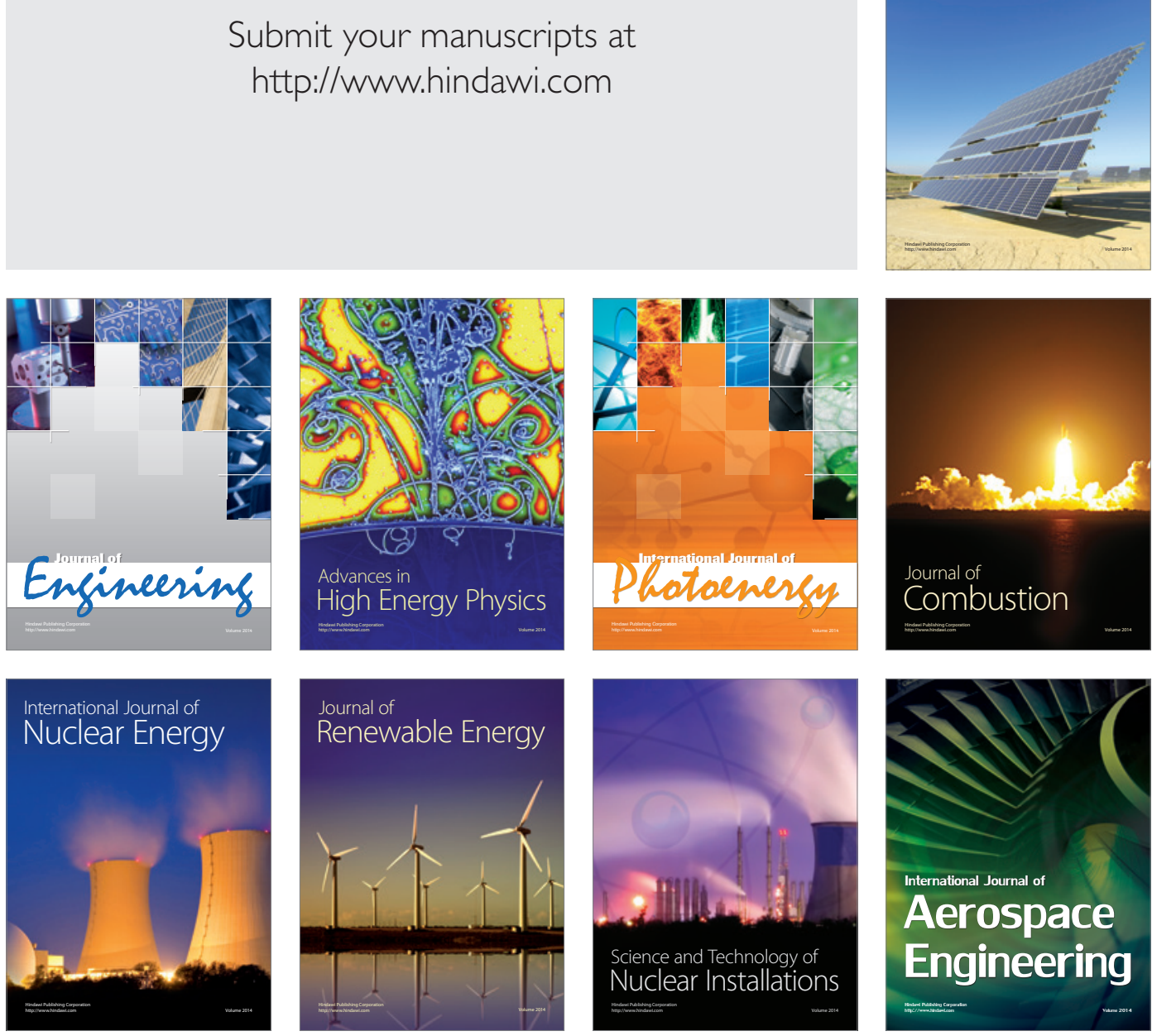